\title{
Economic Inequality and Accessibility to Higher Education
}

\author{
ROBERT M. PIKE*
}

Does Money Matter? Prospects for Higher Education, by Marion Porter, John Porter and Bernard Blishen. Institute for Behavioural Research, York University, Toronto, pp. xiv \& 304

This book contains the first fruits of the large-scale Survey of Ontario Students' Aspirations (SOSA) which was carried out under the direction of John Porter and Bernard Blishen in 1971. In the words of its authors, SOSA involved asking "a sample of about 9000 Ontario high school students about their hopes and aspirations and expectations for education and work, and 3000 of their parents about how they saw their children's educational futures." What is presented here, in a preliminary form, are some of the basic findings of SOSA which the authors believe are highly relevant to the current debate surrounding the development of policies designed to find a more equitable means of distributing the burgeoning costs of higher education. Both Professors John Porter and Bernard Blishen are distinguished in the Canadian sociological milieu for their academic scholarship and for their attempts to apply the findings of sociology to issues of public policy. In Does Money Matter? they cooperate with Marion Porter to produce an essentially policy-oriented document which is both timely and thought-provoking.

In asking the question which forms part of the title of this book, the authors address themselves to the issue of whether or not the educational opportunities of young people in Ontario, and particularly their opportunities for university or college studies, are significantly influenced by economic factors. The significance of this issue is best understood in the light of the prevailing tendency amongst researchers, both in Ontario and elsewhere, to emphasize the influence of so-called "purely cultural" factors rather than economic factors in limiting the educational horizons of lower class youth. In other words, the fact that lower class boys and girls tend to have relatively modest educational aspirations, and are much less likely to enter university than their middle class counterparts, is increasingly explained in terms of deeply-rooted class values and patterns of motivation rather than in terms of lack of money. Of course, it would hardly be reasonable to deny that prolonged economic deprivation amongst the members of a particular social class is likely to have a rather profound effect upon their attitudes and values; from this perspective, therefore, it is probably a false distinction to separate 'culture' from 'economics', as some writers have tended to do. However, the Porters and Blishen fear a growing tendency in Ontario to over-emphasize the non-financial or purely cultural to a point where econom- 
ic inequality is seen now to play no part in limiting the opportunities of lower class youth. Should this happen, then government policies on university tuition fees and student financial assistance may be formulated which, by throwing an additional burden of costs on the student, become essentially regressive in their impact upon educational opportunity.

In their efforts to cast some light on the issues outlined above, the authors proceed to show us that, in their opinion, money does indeed matter in restricting the chances for university education (although, less for low cost community college education) of large numbers of talented high school students in Ontario. This is a task which they perform by demonstrating the impact of such variables as social class, sex, family size, measured intelligence and school performance on the educational and occupational aspirations and expectations of the Grades 8,10 and 12 students who constitute the SOSA sample. They ask also both students and parents a variety of questions pertaining to the financing of post-secondary education. However, whilst the bulk of the book is taken up with the analysis of salient facts and figures drawn from SOSA, it would be wrong to create the impression that it consists of little more than a survey report. On the contrary, the Porters and Blishen preface their empirical analysis with a discussion devoted primarily to the nature of the concept of equality of educational opportunity in which they describe Ontario as a society committed to "equality through accessibility" - that is, to the pursuit of equality through "mass" higher education, which would enable not just the brightest students but, in their words, "all who are willing and capable" to benefit from university or college studies. In turn, this discussion provides a social and philosophical basis from which they form judgments on the issues of equality and inequality which are raised by their empirical findings. It also paves the way for a final chapter which contains proposals for reforms in the areas of tuition fees and student financial assistance which would, so they believe, help to bring the principle of accessibility closer to reality in Ontario.

With respect to the themes outlined above, it is this reviewer's opinion that the most valuable feature of the book lies less in the arguments and proposals pertaining to financing and costs per se (although the value of these is far from negligible) than in its presentation of the most comprehensive body of empirical material pertaining to the impact of social class and sex upon educational opportunity to be published in Ontario for many years. It is, of course, impossible to do justice to the relevant findings of SOSA in the course of a short book review. However, two of the more glaring patterns of inequality which emerged from the responses of the Grade 12 sample are mentioned below for purposes of illustration.

1. The authors found that a Grade 12 student of low mental ability (the bottom third of the ability distribution) who came from a well-off professional or managerial home had almost as much chance of being enrolled in the five-year academic high school programme in Ontario as a Grade 12 student of high mental ability (top third of the ability distribution) who came from a semi-or unskilled manual background; the percentages so enrolled being 72 per cent and 77 per cent respectively. Since this is the programme through which Ontario students usually qualify for university admission (and since only 38 per cent of low ability Grade 12 students who came from semi-or unskilled manual backgrounds were found to be enrolled in the programme), there is a strong indication, as many professors have long suspected, that the Ontario universities cater to a substantial number of dull 
students from wealthy homes whilst missing out on many bright students from the lower classes.

2. Whilst girls in the SOSA sample were generally found to have lower educational and occupational aspirations than boys of the same social class and/or ability level, the authors were led to describe bright girls from semi-and unskilled manual homes as being "the most deprived group in Ontario" in terms of their educational opportunities. This description is borne out by the fact that whilst 44 per cent of lower-class Grade 12 boys in the top third of the ability range expected to go to university after completing high school compared with 75 per cent of higher-class boys from the same ability group, the comparable percentages for lower-class and higher-class girls in the top third of the ability range were 30 per cent and 60 per cent respectively. Furthermore, whilst 11 per cent of able lowerclass Grade 12 boys said that they expected to enter the work-force after completing high school, and 9 per cent said that they wanted to go to work after leaving school, the percentage of able lower-class girls who expected to enter the work-force was far higher ( 32 per cent) although only 18 per cent claimed that this was what they really wanted to do. In general, the low aspirations of the able lower-class girls in the SOSA sample, combined with the large gap between the numbers who expected to enter the work-force after leaving high school and the numbers who wanted to, suggest that the girls have to take second-best when it comes to planning for children's futures in low income families.

In view of their general theme, it is not surprising that the Porters and Blishen are firmly of the opinion that a major reason for these, and similar, patterns of educational inequality is the existence of wide income differentials in the society which constitute a form of discrimination against lower-class youth. In all probability, they are right in their opinion (it would, after all, be very strange if money did not affect students' educational choices and decisions), although many of their arguments are based less upon direct evidence of the impact of financial factors upon educational opportunities than upon indirect evidence of the existence of particular patterns of inequality which would seem logically to have a wholly or partial economic cause. Indeed, where direct evidence does exist - as, for example, in the responses of Grade 12 students to a question asking those who do not intend to go on to a university or college why they have made this decision then the costs of attending a post-secondary institution are certainly found to constitute a substantial barrier to lower-class youth; however, they are less of a barrier than certain academic problems associated with school work. For such reasons as these, the book may fail to change the opinions of those people who are determined to believe that economic inequality is of little significance in limiting the educational horizons of many young Ontarians. Nevertheless, in the light of our earlier comment that economic factors must inevitably play a part in determining class culture and values, the authors' gallant attempt to counter attack the pure culture theme comes none too soon.

To this point, we have said relatively little about the two other main areas of concern in Does Money Matter? - that is, the responses of students and parents to questions pertaining to their attitudes to, and awareness of, the various means of financing a postsecondary education; and also, the authors' suggestions for educational reforms in the areas of tuition fees and student financial assistance. With respect to the first of these areas of concern, the responses to SOSA revealed two main sets of findings: first, that there exists a widespread ignorance of the post-secondary system and financial assistance 
programmes amongst Ontario students, especially in the lower high school grades; and, secondly, that a higher proportion of lower-income students at the Grade 12 level indicated that they were prepared to borrow a significant amount of money in order to finance their post-secondary education than was the case amongst students from the middle and higher income groups. With respect to the first of these sets of findings, the authors are led to emphasize the importance of high school guidance counselling as a means for providing students with adequate information on educational opportunities. The second set of findings is unexpected because it casts doubt on the widespread, but largely unteste liberal assumption that loans constitute a barrier to higher education for lower-income youth: that is that students from less well-off families will be unwilling to go into debt in order to attend university. However, when one thinks about it, a high degree of willingness on the part of low-income people to borrow money is not really so extraordinary in a society where credit is generally used as a means of achieving otherwise unattainable consumption goals. Furthermore, the Porters and Blishen are right in their claim that evidence of willingness to borrow provides no moral justification for the introduction of a student assistance programme with a heavy loan component, since such a programme would burden lower-income students with debts which their classmates from well-off families would be able to avoid.

Turning finally to the authors' proposals for reforms in the areas of tuition fees and student awards, essentially what they propose is a substantial increase in the tuition fees of the Ontario universities (the community colleges are not specifically mentioned here) coupled with an all grant (no loan) student awards scheme based upon parental resources. Such a reform would, they argue, be in accordance with the principles of "accessibility, equity and viability": that is, it would make it possible for lower-income students to attend university; would be more equitable in its effects on students and society than Ontario's existing awards scheme; and finally, would not impose an undue cost burden on the society. More specifically, the imposition of a high level of tuition fees combined with means-tested grant assistance would ensure that high income families could no longe as at present, send their children to university without making financial sacrifices comme surate with those made by low-income families. However, having ensured that the rich pay their fair share, the authors go on to propose that "if the higher income groups can not meet the higher fees and are not prepared to sacrifice their consumption standard, then they might borrow (i.e. through an optional loan scheme) to educate their children." The same loan scheme would be available to students who wished to be free of financial dependency on their parents.

The above proposals might appear radical, but the Porters and Blishen see their implementation as being necessary if Ontario is to make headway in its efforts to achieve equali ty of access to higher education in an economically unequal society. However, what worries this reviewer most, after reading the chapter in which the proposals appear, is not the nature of the proposals themselves - with which he feels much sympathy - nor indeed the question of their political feasibility in a society where wealth and influence walk hand in hand. Rather, what is disturbing is the failure of the authors to specify the position and role of the Ontario community colleges in their scheme of reform. Would the colleges also charge high tuition fees? If not, would they be expected to take the dull higher class students whom the authors hope will be disco: rraged from attending university 
by the high fees? What indeed is the role of the colleges in the pursuit of accessibility? So concerned do the authors appear to be with the question of access to the universities, that these vital questions are never effectively raised in the book, let alone answered.

Finally, at the risk of concluding on a sour note, it should be mentioned that Does Money Matter? contains a number of major errors in pagination which are clearly no fault of the authors. For example, the text on pages 117 and 119 has been transposed. Similarly, page 235 follows immediately after page 134. The book was published by the Institute for Behavioural Research at York University in a format which allows for the speedy production of topical material at a relatively low cost. Too much speed, it seems, and not enough care, went into the production of this publication. 